\title{
'URDU IMPERIALISM' IN PAKISTAN: REALITY OR MYTH
}

\author{
Syeda Sughra NAQVI \\ HEC Scholar at Université de La Rochelle, France, Email: punjtani512@ymail.com
}

\begin{abstract}
The dominant status of Urdu language is a reality in the multilingual society of Pakistan. The mother language of only $7.59 \%$ of the population is the national language of the country that provides opportunity to traditional rivals of Pakistan to provoke ethnic crises, hiding the reality of its being the only source of countrywide communication. The paper highlights the considerable criticism of the language policy in Pakistan that is endangering the 'cultural capital' of local and regional languages through Urdu imperialism. However, contrary to the controversial criticism of its status, the focus of the paper is to argue that Urdu is a natural phenomenon of the region that supports free integrity of the nation and not an imposed one. Its origin, evolution and development as a lingua franca is as natural as the status of English language as a lingua franca for the world. Therefore, it suggests solutions to revive the cultural capital through reforms in education policy in collaboration with language policy rather than criticizing the status of Urdu as the national language, which is the best choice, indeed, because the ubiquity of Urdu is not a myth.
\end{abstract}

Keywords: Multilingualism, Urdu Imperialism, reality/myth, cultural capital

\section{MAIN TEXT}

With the status of national language, Urdu (it was Urdu and Bengali from 1955 to 1971 until East Pakistan became Bangladesh) is the most ubiquitous language in urban areas of Pakistan. It is the language that is used as the medium of instruction in all public schools all over Pakistan - while in the small number of private schools where the English language is the medium of instruction, Urdu is taught as a compulsory subject. Being an official and international language, (English was allowed to be used for official purposes until arrangements are made for its replacement by Urdu [1a]); the importance of English is not ignored and so it too is taught at the higher levels in the public sector, especially to those who seek to study science and technology. In addition, it has become 'a symbol of the elite, sophistication and power.[2a]'

The rationale behind this privilege to Urdu, as given by the government of Pakistan [3a], is that Urdu is so extensively widespread that it is like the first language of all Pakistanis. Moreover, since Urdu is the requirement for most jobs, it is necessary for everyone to have near-native proficiency. Moreover, it is considered an emblem of unity that helps to display the collective identity of Pakistanis. In this emblematic role, it serves the political intention to combat provincial or regional ethnicity, which otherwise would break 
the federation. However, as for the provision that other Pakistani languages may be used, it is explained that the state, being democratic and sensitive to the rights of the federating units, allows the use of provincial languages if desired.

There have been declarations about language policy in various documents in Pakistan-the different versions of the Constitution, statements of government personnel in the legislative assembly, and most of all, in the various documents relating to education policy which have been issued by almost every government. These are stated in the 1973 Constitution as follows:

"(1) The National language of Pakistan is Urdu and arrangements shall be made for its being used for official and other purposes within fifteen years from the commencing day.

(2) Subject to clause (1) the English language may be used for official purposes until arrangements are made for its replacement by Urdu.

(3) Without prejudice to the status of the National language, a Provincial Assembly may by law prescribe measures for the teaching, promotion and use of a provincial language in addition to the national language (Article 251). [4]"

The status of national language for Urdu has always been under question since the partition of 1947 . The State's privileged attitude towards Urdu makes it necessary to 'the domains of power---government, corporate sector, media, and education [2b]' and invites the exclusive criticism and controversies with the introduction of ethnic identity crises for the speakers of languages other than Urdu. It is argued by eminent linguists such as Rahman, Capstick, Torwali and Seifi that if people can have access to education in their home language, all communities will be respected [5]. Morosu (as cited by Seifi, 2014) has the opinion that if children are forced to switch abruptly or transition too soon from learning in their mother tongue to schooling in a second language, their first language acquisition may be weakened or even lost. Even more importantly, their self-confidence as learners and their interest in what they are learning may decline, leading to lack of motivation, school failure and early school drop-out [6].

According to Gouleta, first and second grade textbooks have long passages, complex texts and layouts, and they are written in Urdu using the Nasta-liq script (the 'cursive' nonlinear form of Arabic), which makes it very difficult for young learners to become fluent readers [7].

Another objection against Urdu for its being the national language of Pakistan is that it is, and has always been, the mother tongue of a minority of the population $(7.59 \%$, only) of Pakistan. This minority came from India, mostly after the creation of Pakistan in 1947, and is called Muhajir (refugee or immigrant) [3b]. So, it is found discriminative to give the status of national language to Urdu, ignoring other languages which are spoken by a larger portion of the population than that of Urdu. For instance, Punjabi is spoken by $44.15 \%$ of the population of Pakistan, Pashto by $15.42 \%$, Sindhi by $14.10 \%$, and Saraki by $10.53 \%$ of the total population.

Although the above mentioned objections are valid, and based on undeniable figures, we need to analyse the ground realities in comparison with these quantitative objections to understand the complicated multilingual phenomenon in its historical perspective of the socio-cultural setup in Pakistan that may clarify why Urdu is the best choice for using a national language in the presence of other major local languages.

The understanding of the phenomenon of multilingualism in the multicultural society of Pakistan is very important. As a matter of fact, Pakistan stands at the 31st position among the list of multilingual countries, with a total of 77 languages. 72 out of 77 languages are indigenous while those remaining are immigrants [1b]. The most important indigenous languages include Urdu, Punjabi, Pashto, Sindhi, Saraiki and Balochi while the most popular immigrant languages are English, Arabic and Persian [3c].

To understand the reason why Urdu is privileged by the Government, we need to have a look at its origin and evolution in the form of lingua franca. The origin of Urdu language can be traced to the advent of Islam in the subcontinent in the late first millennium. The first piece of poetry was written by the Persian poet Amir Khusro (1253-1325), and the first Urdu book 'WohMajlis' was written in 1728. The word Urdu was used for the first time by Sirajuddin Ali Khan Aarzo in 1741 [8], while the new lingua franca was named Urdu by the poet Ghulam Hamadani Mushafi , around 1780 [9]. Then it began to develop under the Mughal Empire (1536-1858). The Mughal Emperor Aurangzeb Alamgir (1658-1707) started speaking Urdu fluently and later on tradition was followed by his descendants while his ancestors spoke Persian.

Rahman indicates that Urdu was known as Hindi, Hindavi or Dehlvi before it was named Urdu, from the 13th century [10a]. It developed in the subcontinent with the necessity of communication in the camps of the Mughal Army that consisted of soldiers with a variety of linguistic backgrounds. It didn't have any script until the early 19 th century. At the end of the 18th century, Urdu had taken the place of Persian as the language 
of Muslim culture in India [11]. So Perso-Arabic script was adapted by the Muslims of India while the Hindu community preferred to use Sanskrit script [10b, 12]. It had become a lingua franca that was understood and could be used for communication all over the subcontinent by all communities. For that reason, the British rulers used it as the language of administration to replace the pre-colonial dominant Persian language as a means to counter the influential Persian [13].

During the campaign for an independent Muslim country, Urdu was associated with the Muslims of India while Hindi was considered the language of Hindus. This is also one of the reasons that Urdu was declared the national language of Pakistan. The reason for Pakistan's nationalistic approach to language policy is that Pakistan is not ethnically or linguistically an indistinguishable country. The early policy-makers wanted to create a nation on the basis of "one language, one religion, one nation". But M. Ilyas Khan, a BBC columnist, found a tweet worthy enough to quote in his column that says: "Urdu is not the language of majority; still it is the national language of Pakistan. Even in linguistics, minority is imposed on majority [14]." This is simply an indication of the intentional attempt at provocation for creating ethnic controversy and nothing else, because provincial legislative assemblies have the right to include their own local/regional/provincial language(s) according to the Language policy in Pakistan. There is nothing imposed. For instance, Sahibzada Abdul Qayyum Khan (1864-1937) reported in 1932 that the Pashtuns wanted their children to be instructed in Urdu rather than Pashto [15]. In 2003, the MuttahiddaMajlis e Amal government had chosen Urdu instead of Pashto as the language of the domains of power, including education, in the North West Frontier Province (now this province has been renamed as Khybar Pakhtoon Khwah). The same phenomenon was noticed in Baluchistan. Balochi, Brahvi and Pashto were introduced as the compulsory medium of instruction in government schools in 1990 [16]. Language activists enthusiastically prepared instructional material but on 8 November 1992, these languages were made optional and parents switched back to Urdu [17]. So, it is evidently a voluntary shift, knowing the integral importance of the Urdu language in Pakistan is the only source of communication throughout the country.

As a matter of fact, almost every Pakistani is bilingual with native proficiency in both mother/regional language as well as Urdu, especially in urban areas. Urban parents prefer to communicate with kids in Urdu, considering it a more civilized language, while the mother tongue or regional language of the environment is learnt naturally, by listening to everyone in the surroundings. A small number of elite urban parents speak both English and Urdu with their kids. While in the rural areas where there is a low literacy rate and the majority of parents have never gone to school, Urdu is learnt as the second language while already having native competence in local languages. "Many high-school and college educated Pakistanis are trilingual, being able to speak English and Urdu as well as their own regional language with varying fluency [1c]."

Apart from being a medium of instruction in educational institutions, Urdu is used by print and electronic media as well. It is the main language of national or private TV channels, radio as well as newspapers and magazines along with a few in English. So it is not a completely new language for the students before going to school and beginning to learn it as a second language because most of the kids already have listening and speaking proficiency in Urdu.

As far as Gouleta's argument of 'long passages, complex texts in Nasta-liq script of Urdu' is concerned, every language has its script; easy or difficult, that has to be taught or learnt in school for reading or writing. Even mother tongues cannot be read or written without learning them in a proper way in the educational institutes. However, long and complex texts at early stages in first or second grade of education is really a hurdle for acquiring understanding and fluency, but that is the problem of education policy and inappropriate selection of syllabus, and not of the language policy of Urdu as a national language.

Similarly, Morosu's concerns for lack of confidence, lack of self-esteem, motivation, school failure or early school drop-out are all based on hypotheses regarding language policy in Pakistan. Yes, problems do exist but to address all these problems, what is required is to improve the education policy and not to change the medium of instruction because Urdu is not a strange, foreign or unknown new second language for any citizen of Pakistan. So Morosu's hypothetical frame cannot be applied to the language policy in Pakistan.

The study of the origin, evolution and development of this Hindustani lingua franca highlights the aspect that currently Urdu is not only the mother language of $7.59 \%$ of the immigrant population of Pakistan, but also the common language that is understood and communicated with native proficiency by the vast majority of Pakistanis but also in Hindustan (India) with its different name, Hindi. The major difference between modern Hindi and Urdu is the script: Hindi is written in Sanskrit while Urdu uses Perso-Arabic script and both have the same spoken mode. However, this is opposite to the case of other major languages.

For example, Punjabi is the mother language of $44.15 \%$ of people of Pakistan, who live in the province of Punjab but it is not communicated or even understood by any other than Punjabis. That means it will be a real discrimination if Punjabi is declared as a national language, relative to the rest $(55.85 \%$ of the 
population) of Pakistan living in the other provinces. Similarly, $84.59 \%$ of the population does not know the ABCs of Pashto, $85.9 \%$ of people are unaware of Sindhi, Saraiki is not known by $89.47 \%$, and Balochi's condition is even worse. So, the question pops up, which language other than Urdu is the most appropriate for the status of national language in Pakistan? The answer is obvious, none other than Urdu!

However, the preservation of 'cultural capital [18]' of local/regional languages is a phenomenon that must be taken into serious consideration by both federal and provincial governments. The authorities and policy makers must work in collaboration to not only find answers to the following questions but also to bring them into practice: What reforms are essentially required in education policy to tackle and reduce the gap between learning and acquiring the knowledge? How to develop orthography for small indigenous languages? How to preserve endangered languages in Pakistan? How to improve intercultural communication as well as mutual intelligibility? How to encourage provinces and motivate children to learn other languages, too? And I am sure that the findings of these research questions will not propose to sideline or limit Urdu for the sake of preserving other languages because to remove the hurdles of some languages, it is not necessary to construct barriers against the fabulous, phenomenal lingua franca, namely Urdu. Gandhi said very rightly, "I do not want my house to be walled in on all sides and my windows to be stuffed. I want the cultures of all the lands to be blown about my house as freely as possible. But I refuse to be blown off my feet by any [19]."

\section{REFERENCE LIST: (Ordered as cited in the main text)}

1. Kia (November 21, 2015), The World's Most Multilingual Countries - Ranked, Published in Atlas \& Boots, (1a, 1b, 1c)

2. PouranSeifi (March 25, 2015), Language Policy in Multilingual and Multicultural Pakistan, Publication Date:, Advances in Social Sciences Research Journal, Vol 2, No. 3, (2a, 2b)

3. Tariq Rahman (January 10, 2015), Language policy, multilingualism and language vitality in Pakistan, Quaid-i-Azam University Islamabad, Pakistan--- Retrieved (3a, 3b, 3c)

4. Constitution of Pakistan, (1973), Article 251

5. Capstick T. (2010), Promotion of Linguistic diversity in Pakistan Urged, (The British Council's advisor in Pakistan) Published in International The News

6. Pouran Seifi (2014), Importance of Education in Mother Language for Iranian Bilingual Students, Advances in Social Sciences and Research Journal.1 (8), pg. 156-163

7. Gouleta E. (2013), Linguistic Policy and Practice in Pakistan: Implications for Literary and the Education of Children, Bilingual Basics

8. Abdul Jamil Khan (2006), Urdu/Hindi: An Artificial Divide: African Heritage, Mesopotamian Roots, Indian Culture \& Britain Colonialism, Algora publishing, pg. 178

9. Faruqi, Shamsur Rahman (2003), Sheldon Pollock, ed., A Long History of Urdu Literary Culture Part 1, Literary Cultures in History: Reconstructions From South Asia, University of California Press, p. 806

10. Rahman, Tariq (2011), From Hindi to Urdu: A Social and Political History Karachi, Oxford University Press (10a, 10b)

11. M. Abu Bakar (March 9, 2014), Multilingual Culture of Pakistan, Slideshare, Slide No. 7

12. Rahman, Tariq (2014), Pakistani English (PDF), Quaid-i-Azam University, Islamabad, p. 9

13. Rahman, Tariq (2000), The Teaching of Urdu in British India (PDF), The Annual of Urdu Studies. 15: 55.

14. M. Ilyas Khan ( september 12, 2015), Uncommon Tongue: Pakistan's Confusing Move to Urdu, BBC News Islamabad

15. LAD-F: Legislative Assembly Debates of the North-West Frontier Province (LADF 12 October 1932: 132)

16. LAD-B. Legislative Assembly Debates of Baluchistan LAD-Bal 21 June and 15 April 1990

17. Rahman, Tariq (1996), Language and Politics in Pakistan, Karachi, Oxford University Press.

18. Bourdieu, Pierre (1991), Language and Symbolic Power. (ed.) John B. Thompson. Trans. From the French by Gino Raymond and Mathew Adamson. Cambridge: Policy Press. Edition used, (1994 reprint)

19. Mahatma Gandhi (1920), No Culture Isolation For Me, Newspaper 